\title{
Endotoxin levels in homes and classrooms of Dutch school children and respiratory health
}

José H. Jacobs, Esmeralda J.M. Krop, Siegfried de Wind, Jack Spithoven and

Dick J.J. Heederik

Affiliations: Institute for Risk Assessment Sciences, Division of Environmental Epidemiology, Utrecht University, Utrecht, The Netherlands.

Correspondence: J.H. Jacobs, Institute for Risk Assessment Sciences, Utrecht University, P.0. Box 80178, 3508 TD Utrecht, The Netherlands. E-mail: j.h.jacobsQuuu.nl

ABSTRACT Several studies describe indoor pollutant exposure in homes and to a lesser extent in schools. Population studies that include both environments are sparse. This study aims to assess endotoxin levels in primary schools and homes of children. Endotoxin was also studied in relation to asthma and sensitisation.

10 schools with (index) and without (reference) dampness were selected, based on reports and inspections. Cases and controls were selected from 169 homes based on the presence or absence of asthmalike symptoms of children. Classroom and bedroom airborne settled dust was sampled using electrostatic dust fall collectors.

Average endotoxin levels in schools ranged from 2178 to 6914 endotoxin units (EU) $\cdot \mathrm{m}^{-2}$ per week compared with $462-1285 \mathrm{EU} \cdot \mathrm{m}^{-2}$ per week in homes. After mutual adjustment for home and school endotoxin, school endotoxin was positively associated with nonatopic asthma (OR 1.11, 95\% CI 0.97-1.27), while no associations with endotoxin were found at home.

The high endotoxin levels in schools compared with homes indicate that exposure at school can contribute considerably to environmental endotoxin exposure of children and teachers. Our results also suggest that endotoxin in schools may be associated with nonatopic asthmatic symptoms in pupils, although the results require reproduction because of the modest sample size.

@ERSpublications

School endotoxin levels can contribute to exposure of children and teachers, causing nonatopic asthmatic symptoms http://ow.ly/lweoq

Received: May 302012 | Accepted after revision: Oct 052012 | First published online: Oct 252012

Support statement: This work was supported by the European Commission as part of the HITEA project, grant agreement number 211488 under the Seventh Framework Programme, Topic ENV.2007.1.2.1.1 (school exposure measurements and questionnaire data) and the Netherlands Asthma Foundation, project number 3.2.08.018 (home exposure measurements and serological data).

Conflict of interest: None declared.

Copyright @ERS 2013 


\section{Introduction}

School is, after home, an important indoor environment for young children and may contribute to children's exposure to various pollutants. Several studies describe the variety and extent of indoor pollutant exposure in homes and to a lesser extent in schools. Using levels from a single microenvironment may, however, not adequately represent daily personal exposure in children and other environments also need to be taken into account. However, studies that include both home and school environments simultaneously are sparse.

Poor indoor air quality in schools may affect the performance and attendance of students [1]. Home dampness and elevated microbial exposures have been associated with respiratory health effects. Specific causative agents have not been identified [2], but most observations are available for endotoxin [3,4]. In schools, allergen levels have been studied most extensively [5], but only few studies examined endotoxin or levels of other microbial markers [6-13]. Endotoxin is a cell wall component of the outer membrane of Gram-negative bacteria and is present in indoor environments as constituents of house dust. In homes, endotoxin has been linked to decreased rates of sensitisation, asthma and hay fever in early childhood [14-16], but endotoxin is also associated with increased symptom prevalence and nonallergic asthma [14, 17]. In most studies, endotoxin in schools was studied in a small number of measurements, and endotoxin was mainly measured in floor dust $[6,8-11]$, which is a poor proxy of inhalatory endotoxin exposure, as the majority of classroom floor dust consists of large and heavy particles (sand and breadcrumbs). Only one recent study measured floor endotoxin levels in homes and schools of asthmatics; the study found higher endotoxin levels in school compared with the homes of asthmatics. However, the associations between endotoxin levels and respiratory outcomes were not studied [13].

The present study is part of the European project, Health Effects of Indoor Pollutants: Integrating microbial, toxicological and epidemiological approaches (HITEA) [18], and is designed to identify the role of dampness-related indoor air quality in primary schools in relation to respiratory health in pupils and teachers across Europe. The aim of this study was to assess indoor endotoxin levels and compare levels in the primary schools and homes of children in the Netherlands. In addition, we explored associations with asthmatic symptoms and sensitisation.

\section{Methods}

Selection of schools

This study is a Dutch extension of the HITEA project. A more detailed description of the school selection is given elsewhere [18]. The aim was to select schools with (index) and without (reference) moisture, mould and/or dampness problems, representing the most strongly moisture-damaged schools and control schools as previously described [19].

Briefly, schools were invited via a letter addressed to the school principals, to complete a questionnaire by regular mail, telephone interview or internet, focusing on current and past dampness, moisture damage and mould problems, and collecting extensive general information on the school buildings.

Based on this questionnaire, schools were selected and building inspections were performed by centrally trained research personnel and included walkthroughs, using pre-designed checklists and making simple indoor climate measurements. Based on severity, extent and location of the dampness observations during the school inspections, schools were categorised either as affected by moisture damage/dampness (index schools) or as nonaffected (reference schools), as previously described [19].

In the Netherlands, five index schools and five reference schools were included for detailed exposure and health characterisation.

\section{Study population: selection of cases and controls}

A clarification of the study design is presented in figure 1. Participants were selected out of a population of 796 children who had already participated in a questionnaire survey and had complete lung function data. The protocol was based on the International Study of Asthma and Allergies in Childhood (ISAAC) study [20]. Lung function test were performed at school according to the European Respiratory Society guidelines [21]. All children were aged between 6 and 12 years. Parents from 84 children with asthma-like symptoms (cases) and 170 children without symptoms (controls), as reported in a questionnaire study, were invited by regular mail to participate with home exposure measurements. Children were considered asthmatic when a positive answer was given to at least one of following items: 1) wheezing or whistling in the chest in the past 12 months; 2) ever had asthma; 3) using any medicines, pills, inhalers or other medication for wheezing or asthma in the past 12 months; and 4) dry cough at night, apart from a cough associated with a cold or chest infection in the past 12 months. 
10 schools (5 index, 5 reference)

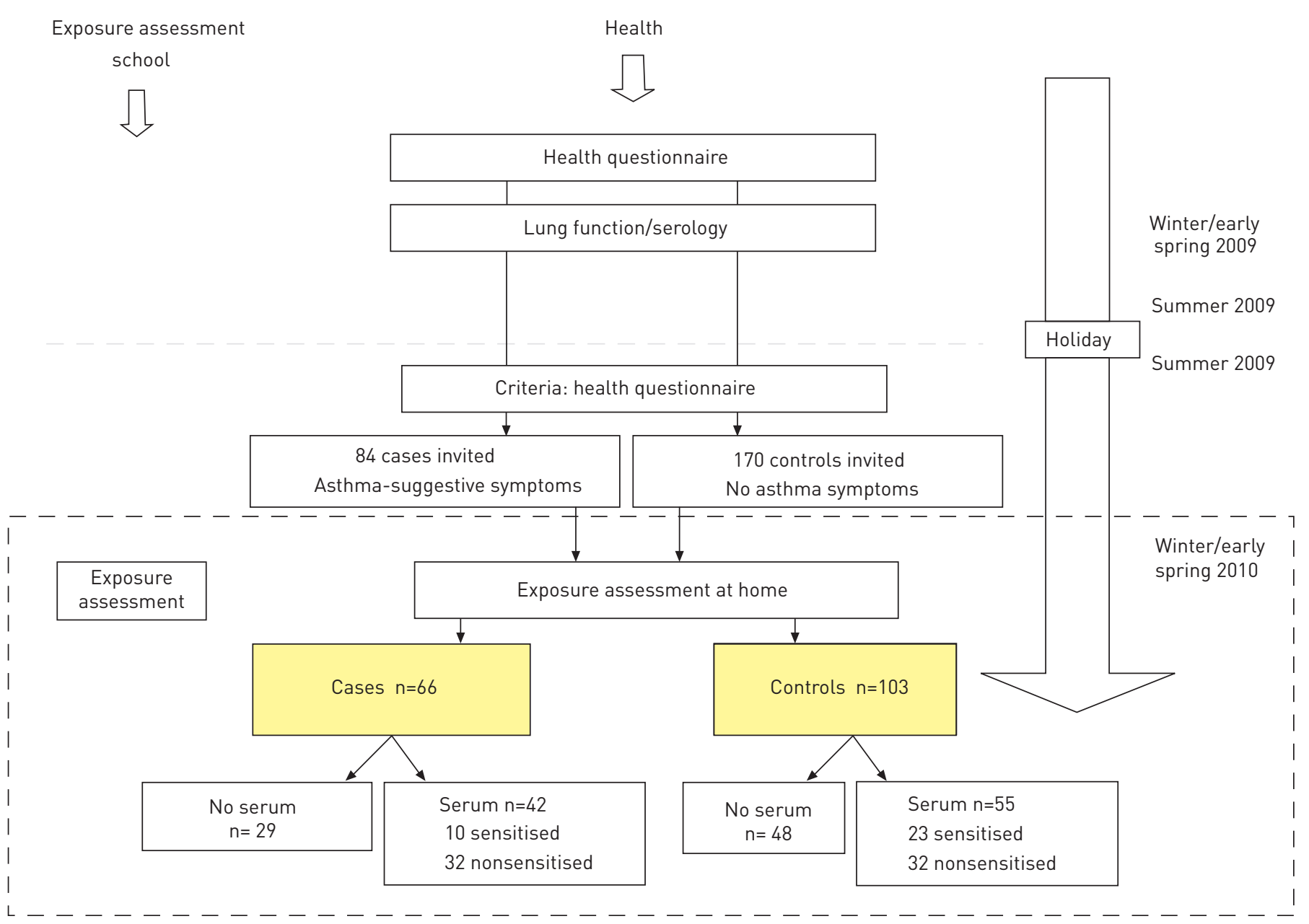

FIGURE 1 Flow chart of the study design.

Children were also invited to donate venous blood samples for immunoglobulin (Ig)E analysis and 97 (57\%) of the invited children participated. The study protocol was approved by the Medical Ethical Committee of the Utrecht Medical Center, Utrecht, the Netherlands, and complied with all requirements of international regulations.

\section{IgE measurements}

Blood sampling was performed at school. Aeroallergen-specific IgE serum concentrations were measured by an earlier developed enzyme immunoassay, which has been validated against commercially available immunoassays [22]. IgE levels were screened against house dust mites, cat epithelium, dog dander, birch and grass pollen mixture. A child was considered sensitised to a specific allergen if their IgE test result exceeded an optical density of 0.050 after correction.

\section{Dust sampling}

School and home endotoxin was measured during March and April 2010. Airborne settled dust was passively sampled with electrostatic dustfall collectors (EDCs), a recently developed low cost sampling approach that consists of a folder with two electrostatic microfibre cloths, each with a surface area of $0.02083 \mathrm{~m}^{2}$ [23]. In all schools, dust was collected simultaneously during an 8-week sampling period. Trained field workers placed EDCs at a minimum height of $150 \mathrm{~cm}$ from the floor and away from windows, doors, ventilation ducts and heating [23], targeting $\sim 15$ locations and covering all areas, location types and grades in a school. Relative humidity was measured for 1 week in one classroom per school. EDCs were 
closed after sampling and stored at room temperature for a maximum of 2 weeks. After removal from the EDC, cloths were stored at $-20^{\circ} \mathrm{C}$ until analysis.

EDCs were also applied for dust sampling in homes of the participating children according to previously used home protocols over a 2-week period [23, 24]. These EDCs were sent by regular mail, accompanied by an invitation letter, detailed sampling instructions and a short questionnaire that included questions about the measurement and home and household characteristics. EDCs were placed in the child's bedroom, at a minimum height of $150 \mathrm{~cm}$ and away from windows, doors, ventilation ducts and heating. After sampling, parents returned the EDC and questionnaire by mail. Home EDCs were handled similarly to the school samples.

\section{Sample extraction and analysis}

Endotoxin was extracted from the EDC as described elsewhere [23, 24]. Briefly, cloths were incubated for $60 \mathrm{~min}$ in $20 \mathrm{~mL}$ pyrogen-free water (B. Braun NPBI, Oss, the Netherlands) in an end-over-end roller. After centrifugation for $15 \mathrm{~min}$ at $1000 \times \mathrm{g}$, the supernatant was stored in $200 \mu \mathrm{L}$ aliquots in pyrogen-free glass tubes at $-20^{\circ} \mathrm{C}$ until analysis.

Extracts were tested for endotoxin with the limulus amoebocyte lysate (LAL) assay (Lonza Group, Basel, Switzerland) according to the manufacturer's protocol. Resulting endotoxin units (EU) per mL values were converted into $\mathrm{EU} \cdot \mathrm{m}^{-2}$ per week. The limit of detection of the assay was assessed at $150 \mathrm{EU} \cdot \mathrm{m}^{-2}$ per week. None of the 148 school samples and three out of 169 home samples were below the limit of detection and were assigned a value $100 \mathrm{EU} \cdot \mathrm{m}^{-2}$ per week.

\section{Statistical methods}

Endotoxin levels were $\log _{10}$-transformed because of the skewed distribution. Endotoxin was measured in the classroom of $75 \%$ of our study population. Missing levels were replaced by grade averages or, when unavailable, the average of classrooms in the same area within the school or the classroom school average was used. All classrooms were occupied by the same group of pupils during the week.

The MIXED procedure was used to explore the variability of endotoxin levels and to study potential determinants affecting endotoxin levels. Associations between exposure in classrooms and health outcomes were analysed by the GENMOD procedure. Odds ratios were calculated for an interquartile range increase in $\log _{10}$-transformed endotoxin exposure, which corresponded with a $\left(10^{0.29}\right) 2.0$-fold exposure increase in school levels and a $\left(10^{0.57}\right) 3.7$-fold endotoxin exposure increase in home levels. "School" was included as random effect to adjust for correlation between exposure and health outcomes of children within the same school. Children from schools affected by moisture might be oversampled due to the study design, so all models were adjusted for the school's moisture status. Potential confounders were selected based on prior knowledge and whether they were significantly associated with the outcome of interest. Covariates were retained in the final model if they substantially $(>10 \%)$ modified the crude odds ratio.

The shape of the association between endotoxin exposure and health outcomes was further studied by generalised additive modelling (smoothing), with the degrees of freedom set at 2 . All statistical analyses were performed with SAS version 9.2 (SAS Institute Inc., Cary, NC, USA).

\section{Results}

A total of 148 school samples, including 97 classroom samples and 169 home samples (the response rate for homes was 67\%) were included. The weekly average relative humidity in classrooms was 37\% (minimummaximum 30-49\%). Responders and nonresponders did not differ with regard to most home characteristics and reported parental allergies. Available questionnaire survey data indicated that nonresponders had smoked more inside the home and reported mould odour more often (smoking 20\% versus 11\%; mould odour 33\% versus $20 \%$ ). No significant differences were observed in characteristics between children who provided serum and those who did not.

Endotoxin levels in schools were significantly higher in full-time classrooms and in lower grades (table 1). Home endotoxin levels were higher in larger households and in older houses. Other characteristics, such as floor type, the presence of pets in the home and smoking inside the home, were not associated with endotoxin EDC levels.

Endotoxin levels in classrooms were on average 4.5-fold higher $(\mathrm{p}<0.05)$ than in bedrooms. Average school levels ranged from 2178 to $6914 \mathrm{EU} \cdot \mathrm{m}^{-2}$ per week (geometric mean compared with 462 to $1285 \mathrm{EU} \cdot \mathrm{m}^{-2}$ per week in homes (geometric mean per school). School and home endotoxin levels were significantly higher (30\% and 20\%, respectively) in the index compared with the reference category. The correlation between home and school endotoxin levels was low $(r=0.09 ; \mathrm{p}=0.29)$. Home endotoxin levels did not clearly differ between different schools.

Of the children with asthma-like symptoms, 17\% reported wheeze at present, $20 \%$ had asthma (ever- or doctor-diagnosed), 20\% had used asthma medication last 12 months and 39\% reported dry cough at night 


\section{TABLE 1 Association between general characteristics and endotoxin levels in schools and} homes from the study participants (univariate analysis)

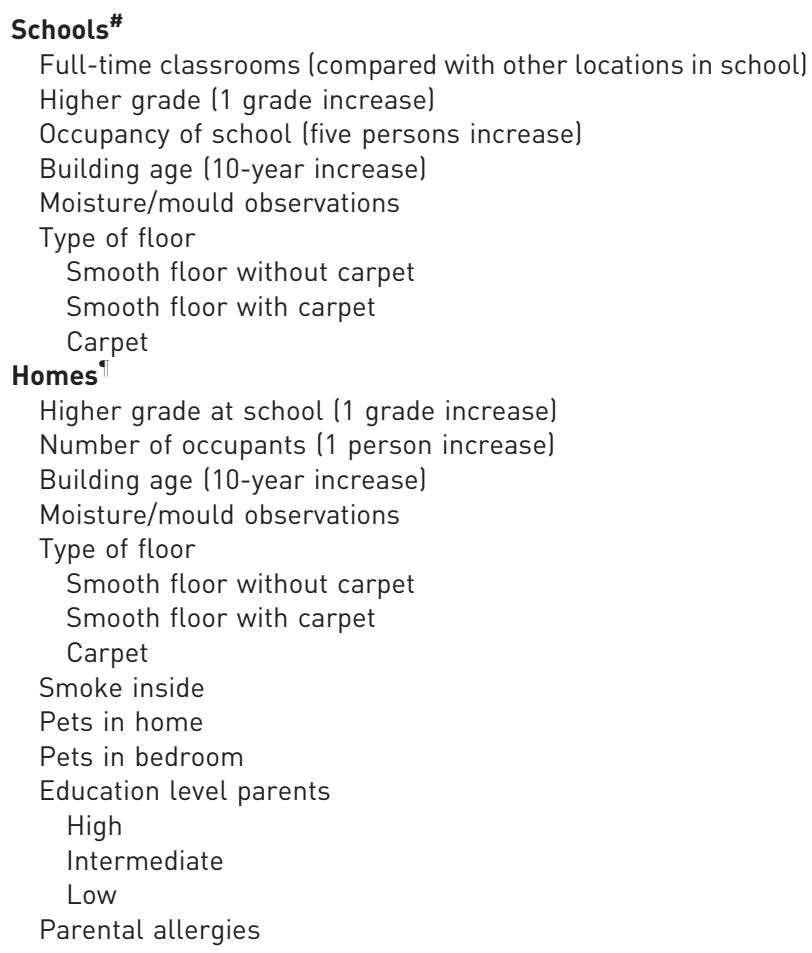

$1.21(1.13-1.3)$

$0.98(0.97-1.00)$

$1.04(0.99-1.10)$

$1.00(0.97-1.03)$

$1.15(0.95-1.39)$

Reference NA

$0.96(0.67-1.39)$

$1.03(0.98-1.07)$

$1.14(1.06-1.22)$

$0.96(0.94-0.99)$

$1.02(0.90-1.16)$

Reference

$1.03(0.90-1.18)$

$0.99(0.85-1.15)$

$1.00(0.91-1.09)$

$1.04(0.93-1.17)$

$0.90(0.78-1.04)$

Reference

$0.89(0.79-1.01)$

$1.04(0.80-1.35)$

$1.03(0.89-1.18)$

Data are presented as geometric mean ratio (95\% confidence interval). NA: not available. ${ }^{\#}: \mathrm{n}=148 ;{ }^{\top}: \mathrm{n}=169$.

during the last 12 months. The forced expiratory volume in $1 \mathrm{~s}$ of those with asthmatic symptoms was $2 \%$ lower, adjusted for sex and age. Surprisingly, nonasthmatic children more frequently showed elevated serum IgE levels, although the difference was not significant ( $42 \%$ versus $24 \%$; $=0.11$ ) (table 2 ).

Home endotoxin levels tend to be lower in children with asthma-like symptoms compared with children with no asthmatic symptoms, but differences were only borderline significant for atopic asthma (fig. 2). In schools, classroom endotoxin loads were higher for children with asthma compared with nonasthmatic children; however, differences were only (borderline) statistically significant for nonsensitised asthmatics (geometric mean $=4049$ versus $3261 \mathrm{EU} \cdot \mathrm{m}^{-2}$ per week, $\mathrm{p}=0.09$ ). There was no difference in endotoxin home or school levels between sensitised and nonsensitised children.

Logistic regression modelling (table 3 ) showed that home endotoxin tended to be inversely associated with asthma symptoms, but only for atopic asthma (adjusted odds ratio $=0.87(0.68-1.11)$ ). School exposure was positively associated with nonatopic asthma symptoms (adjusted odds ratio $=1.11(0.97-1.27)$ ), but not with atopic asthma. Sensitisation, without taking into account case (asthma) status, was not associated with endotoxin levels at home or at school (data not shown). Splines generally showed a decrease in prevalence of asthma symptoms with increasing home endotoxin levels (fig. 3). Trends were strongest for atopic asthma symptoms. Asthma symptoms generally increased with increasing classroom endotoxin levels (fig. 3). This seemed attributable to asthma symptoms in nonatopics. In contrast, the prevalence of atopic asthma and asthma without taking sensitisation status into account decreased at the highest classroom levels.

\section{Discussion}

The present study shows that endotoxin levels were considerably higher in schools than in homes. Furthermore, endotoxin levels were associated with asthma status; school endotoxin levels tended to be higher for children with asthma-like symptoms. Associations were strongest for nonatopic asthma and remained significant after mutual adjustment of children's bedroom and school levels. Determinants associated with home levels were the number of people in the household and the construction year of the house, while in schools, it was mainly the grade and occupancy that affected endotoxin levels.

Although this is an exploratory study with a relatively limited number of home measurements, the major strength of this study is that we measured endotoxin levels in schools and homes in parallel among the same 
TABLE 2 General characteristics of children with symptoms indicative for asthma

\begin{tabular}{|c|c|c|}
\hline & \multicolumn{2}{|c|}{ Asthma-suggestive symptoms } \\
\hline & Controls & Cases \\
\hline Subjects & 103 & 66 \\
\hline \multicolumn{3}{|l|}{ Basic characteristics } \\
\hline Males & $53(51)$ & $29(44)$ \\
\hline Age years & $8.8 \pm 1.4$ & $8.3 \pm 1.4$ \\
\hline BMI $\mathrm{kg} \cdot \mathrm{m}^{-2}$ & $15.9 \pm 1.9$ & $16.1 \pm 2.1$ \\
\hline Number older siblings & $0(1)$ & $1(1)$ \\
\hline \multicolumn{3}{|l|}{ Parental education } \\
\hline Low & 7 (7) & 2 (3) \\
\hline Intermediate & $28(28)$ & $29(44)$ \\
\hline High & $66(65)$ & $35(53)$ \\
\hline \multicolumn{3}{|l|}{ Parental smoking } \\
\hline Current & $12(12)$ & $5(8)$ \\
\hline During first year of child's life & $11(11)$ & $5(8)$ \\
\hline During pregnancy & $5(5)$ & $7(11)$ \\
\hline \multicolumn{3}{|l|}{ Birthweight kg } \\
\hline$<2.5$ & $5(5)$ & $4(6)$ \\
\hline $2.5-4.0$ & $82(80)$ & $51(78)$ \\
\hline$>4.0$ & $16(16)$ & $9(14)$ \\
\hline Daycare attendance & $43(42)$ & $23(35)$ \\
\hline Parental asthma & $27(26)$ & $18(27)^{\S}$ \\
\hline Farm animal contact first year & $13(13)$ & $7(11)$ \\
\hline \multicolumn{3}{|l|}{ Pets present in home } \\
\hline Current & $47(46)$ & $34(52)$ \\
\hline During first year & $48(47)$ & $30(45)$ \\
\hline \multicolumn{3}{|l|}{ Mould spots/odour at home } \\
\hline During last 12 months & $19(19)$ & $19(29)$ \\
\hline Ever & 30 (29) & $25(38)$ \\
\hline \multicolumn{3}{|l|}{ Water damage at home } \\
\hline During last 12 moths & $25(24)$ & $18(28)$ \\
\hline Ever & 40 (29) & $29(45)$ \\
\hline Sensitisation $>1$ common allergen ${ }^{+}$ & $23(42)$ & $10(24)^{\S}$ \\
\hline
\end{tabular}

Data are presented as $\mathrm{n}, \mathrm{n}(\%)$, mean $\pm \mathrm{SD}$ or median (interquartile range). ${ }^{\#}$ : not all categories add to the total sample size due to missing information; " because the distribution is skewed to the right, the median is reported instead of the mean; ${ }^{+}$: serum information was available from 97 children; ${ }^{\S}: p \leqslant 0.10$ different from controls.
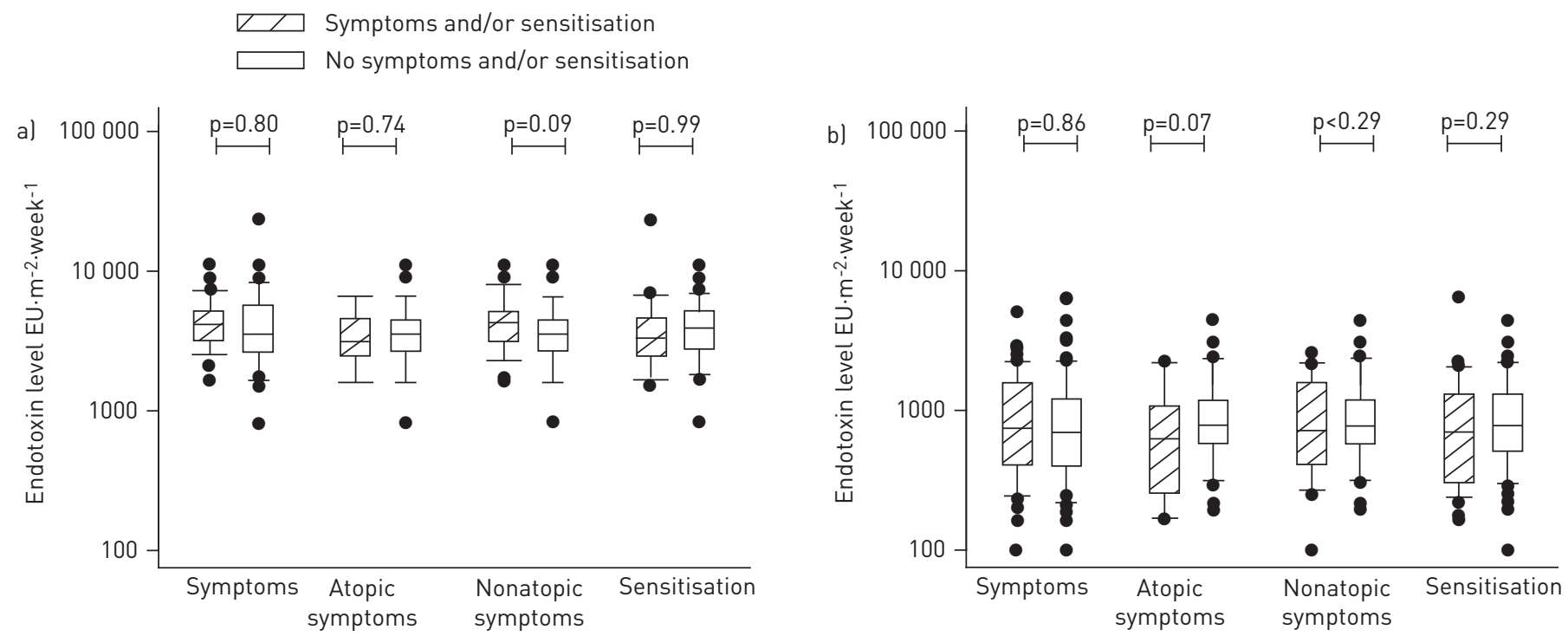

FIGURE 2 Airborne endotoxine levels in a) schools and b) homes by health status. EU: endotoxin units. 
TABLE 3 Association between endotoxin levels at home and at school, and asthma-suggestive symptoms

\begin{tabular}{|c|c|c|c|}
\hline \multirow[t]{2}{*}{ Endotoxin exposure } & \multirow[t]{2}{*}{ Asthma symptoms ${ }^{\#}$} & \multicolumn{2}{|c|}{ Asthma symptoms including sensitisation status } \\
\hline & & Atopic asthma & Nonatopic asthma \\
\hline Cases/controls $\mathrm{n}$ & $66 / 103$ & $10 / 32$ & $23 / 32$ \\
\hline $\begin{array}{l}\text { In classroom lof participants with home } \\
\text { endotoxin measurements) }\end{array}$ & $1.06(0.97-1.17)$ & $1.08(0.96-1.21)$ & $1.13(1.01-1.26)$ \\
\hline At home & $1.03(0.92-1.16)$ & $0.83(0.62-1.11)$ & $0.98(0.74-1.3)$ \\
\hline \multicolumn{4}{|l|}{ Endotoxin exposure mutually adjusted } \\
\hline School & $1.06(0.97-1.16)$ & $1.12(1.02-1.23)$ & $1.15(1.02-1.3)$ \\
\hline Home & $1.02(0.91-1.15)$ & $0.81(0.62-1.06)$ & $0.92(0.8-1.05)$ \\
\hline \multicolumn{4}{|l|}{$\begin{array}{l}\text { Endotoxin exposure mutually adjusted and } \\
\text { adjusted for additional confounders }\end{array}$} \\
\hline School & $1.06(0.98-1.15)$ & $0.99(0.88-1.11)$ & $1.11(0.97-1.27)$ \\
\hline Home & $1.09(0.96-1.24)$ & $0.87(0.68-1.11)$ & $0.92(0.76-1.11)$ \\
\hline
\end{tabular}

Data are presented as OR (95\% CI), unless otherwise stated. " : reference categories (controls) were no asthma symptoms, and not sensitised and no asthma symptoms, respectively. An interquartile range increase corresponds with a factor 2.0 endotoxin increase in schools and a factor 3.7 increase in homes. ": adjusted for age, sex, building year of home, number people in household, smoking inside home, pets inside bedroom, parental allergies, parental education, school grade and dampness status of the school.

children. Our results confirm the findings from a recent study that endotoxin levels in schools were higher than in homes [13]. In our study, endotoxin levels were on average more than four fold higher in schools, and this included schools without raised dampness levels, where levels were also four times higher compared with homes. An earlier survey showed that prolonged exposure of the EDC led to underestimation of endotoxin levels [24]. In our survey, sampling time between homes and schools was different (2 versus 8 weeks), and we converted our results to a 1-week sampling time by dividing levels by 2 and 8 , respectively. Accounting for this underestimation would have led to higher school endotoxin levels. This means that the difference in endotoxin levels between school and home might be even be larger than observed.

Domestic endotoxin has been associated with home dampness, pet ownership, farm animal contact, environmental tobacco smoke exposure, family size and socioeconomic status [3, 4]. Schools differ from homes in function, building characteristics, maintenance level and occupant density, so other determinants might also affect school endotoxin levels. Shedding of human skin or dirt brought in by shoes are probably important sources of endotoxin in classrooms, while in homes, endotoxin is also derived from pets.

We found a poor correlation between home and school endotoxin levels, where home levels were lower. This makes it unlikely that children transport endotoxin via their clothing from home to school, as has been previously observed for cat allergens [25]. No other studies have characterised in detail factors affecting endotoxin levels in schools. However, some studies found high dust levels, which contain endotoxin, in
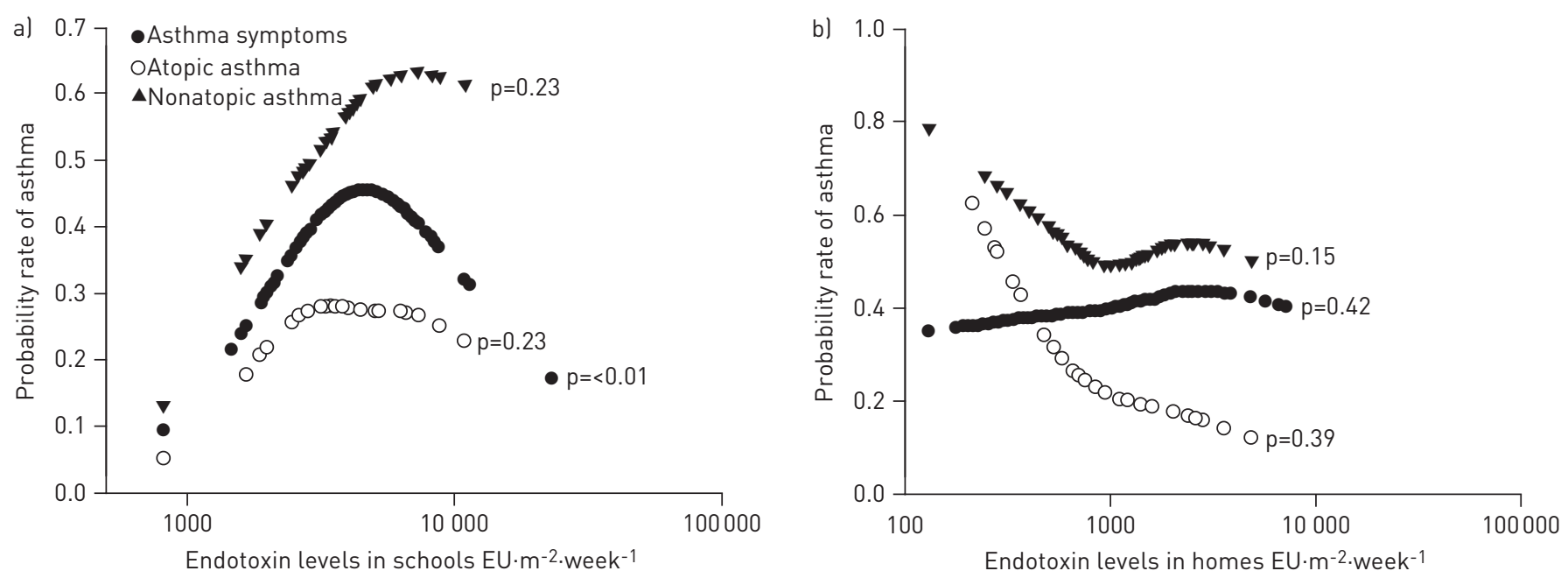

FIGURE 3 Nonlinear associations (degrees of freedom =2) between asthmatic symptoms, atopic asthma and nonatopic asthma in children and endotoxin exposure a) in schools and b) in homes. Nonlinear associations for endotoxin levels with asthma at school were statistically significant $(p<0.05)$. EU: endotoxin units. 
schools. The levels of average airborne particles with a 50\% cut-off aerodynamic diameter of $10 \mu \mathrm{m}$ in classrooms ranged from 65 to $157 \mu \mathrm{g} \cdot \mathrm{m}^{-3}$ in different European countries [26, 27], and were considerably higher in classrooms compared with homes [28]. High dust levels in schools might be caused by resuspension of particles caused by activity of pupils, and cleaning frequency might also affect dust levels [26, 27]. These are also likely to be explanations for the high endotoxin levels in schools in our study.

We generally found a positive association between asthma symptoms and classroom endotoxin levels, while studies in homes showed that endotoxin exposure in early life might be protective for the development of having asthma and other respiratory allergies [13-15]. Possible explanations for these different associations might exist. First, the composition of endotoxin may be different in schools. It has been well established that different microorganisms produce different chain lengths of endotoxin and these might have a different biological potency [29]. A study in 10 Chinese schools found a negative association between asthmatic symptoms and short-chain endotoxins (10-carbon, 12-carbon and 14-carbon lipopolysaccharide), while positive associations were observed with longer chain lengths [5]. A 2-year follow-up study observed a protective effect of bacterial compounds (including lipopolysaccharide) on the development of mucosal and general symptoms [7]. These findings have not been yet replicated in other studies, but might not easily be generalised. For instance, studied classrooms were considerably more crowded ( $\sim 50$ students per classrooms) and other aspects probably differed as well (such as climate, building structure and maintenance), which may have influenced the microbial exposure both qualitatively and quantitatively, although a detailed comparison is not possible because different agents have either been measured or techniques differed.

Secondly, some studies have demonstrated that in addition to the protective effects of endotoxin on allergies, high endotoxin exposure may also cause nonatopic respiratory effects [14, 17], which might explain our findings that the relatively high school levels were mainly associated with nonatopic asthma. The overlap in exposure distributions between schools and homes is, however, considerable and, therefore, seems a less likely explanation. Conversely, this may in part also be the result of an adjustment for different sampling times, and the adjustment needs further verification. Thirdly, timing and duration of endotoxin exposure might be different for schools and homes. Home levels are more likely to reflect longer-term exposure to microbial agents from birth onwards, whereas endotoxin exposure at schools reflect more recent exposure that has occurred during the past few years, i.e. since starting-school age. Fourthly, in addition to endotoxin, other microbial agents might also affect occupants' health. Fungal exposure in schools has been adversely related to respiratory health effects in a few studies [7-9]. Because the schools in our study were selected on the basis of moisture problems, indoor pollution may differ between schools and homes, and endotoxin exposure at school may interact with other (dampness-related) agents [30]. Conversely, endotoxins are still considered to be one of the more potent microbial agents. Large and especially longitudinal studies, with more refined clinical data, are needed to explore the above-mentioned potential explanations further.

Exposure has probably been estimated adequately over a relatively long period of time. Previous studies have shown that endotoxin levels measured with the EDC were relatively constant over time [4]. Also, none of the participants moved during the year before the home-exposure measurements. Additionally, avoidance behaviour (reverse causation), i.e. measures to reduce exposure in persons with respiratory problems, might bias the results, especially in homes. Comparing asthmatic and nonasthmatic children regarding potentially avoidance-related characteristics at home, such as smoking, having pets, cleaning frequency and the use of carpet in the bedroom, indicated that avoidance is probably not a major concern, but cannot be ruled out. Reverse causation in schools is unlikely, as parents are unlikely to select the school on hygiene status.

In conclusion, this study showed high endotoxin levels in schools compared with homes, which indicates that exposure during the school day may contribute substantially to the total endotoxin load in children and teachers. This makes endotoxin exposure in schools interesting to study with regards to respiratory health of pupils and teachers. Our results also suggest that endotoxin in schools may be associated with asthmatic symptoms in pupils, although the sample size of our study is relatively low. To confirm these findings and explore whether other agents might also affect respiratory health, additional exploration of these results is needed in a larger dataset, including more detailed (longitudinal) exposure and health measurements in the other schools of the three countries of the HITEA study, and also in other school studies.

\section{References}

1 Mendell MJ, Heath GA. Do indoor pollutants and thermal conditions in schools influence student performance? A critical review of the literature. Indoor Air 2005; 15: 27-52.

2 Mendell MJ, Mirer AG, Cheung K, et al. Respiratory and allergic health effects of dampness, mold, and dampnessrelated agents: a review of the epidemiologic evidence. Environ Health Perspect 2011; 119: 748-756.

3 Park JH, Spiegelman DL, Gold DR, et al. Predictors of airborne endotoxin in the home. Environ Health Perspect 2001; 109: 859-864. 
Thorne PS, Cohn RD, Mav D, et al. Predictors of endotoxin levels in U.S. housing. Environ Health Perspect 2009; 117: 763-771.

5 Salo PM, Sever ML, Zeldin DC. Indoor allergens in school and day care environments. J Allergy Clin Immunol 2009; 124: $185-192$.

6 Zhao Z, Sebastian A, Larsson L, et al. Asthmatic symptoms among pupils in relation to microbial dust exposure in schools in Taiyuan, China. Pediatr Allergy Immunol 2008; 19: 455-465.

7 Zhang X, Zhao Z, Nordquist T, et al. A longitudinal study of sick building syndrome among pupils in relation to microbial components in dust in schools in China. Sci Total Environ 2011; 409: 5253-5259.

8 Cai GH, Hashim JH, Hashim Z, et al. Fungal DNA, allergens, mycotoxins and associations with asthmatic symptoms among pupils in schools from Johor Bahru, Malaysia. Pediatr Allergy Immunol 2011; 22: $290-297$.

9 Simoni M, Cai GH, Norback D, et al. Total viable molds and fungal DNA in classrooms and association with respiratory health and pulmonary function of European schoolchildren. Pediatr Allergy Immunol 2011; 22: 843-852.

10 Rabinovitch N, Liu AH, Zhang L, et al. Importance of the personal endotoxin cloud in school-age children with asthma. J Allergy Clin Immunol 2005; 116: 1053-1057.

11 Rullo VEV, Rizzo MC, Arruda LK, et al. Daycare centers and schools as sources of exposure to mites, cockroach, and endotoxin in the city of São Paulo, Brazil. J Allergy Clin Immunol 2002; 110: 582-588.

12 Foarde K, Berry M. Comparison of biocontaminant levels associated with hard vs. carpet floors in nonproblem schools: results of a year long study. J Expo Anal Environ Epidemiol 2004; 14: Suppl. 1, S41-S48.

13 Sheehan WJ, Hoffman EB, Fu C, et al. Endotoxin exposure in inner-city schools and homes of children with asthma. Annals Allergy Asthma Immunol 2012; 108: 418-422.

14 Braun-Fahrlander C, Riedler J, Herz U, et al. Environmental exposure to endotoxin and its relation to asthma in school-age children. N Engl J Med 2002; 347: 869-877.

15 Gehring U, Strikwold M, Schram-Bijkerk D, et al. Asthma and allergic symptoms in relation to house dust endotoxin: Phase Two of the International Study on Asthma and Allergies in Childhood (ISAAC II). Clin Exp Allergy 2008; 38: 1911-1920.

16 Douwes J, Le Gros G, Gibson P, et al. Can bacterial endotoxin exposure reverse atopy and atopic disease? J Allergy Clin Immunol 2004; 114: 1051-1054.

17 Tavernier G, Fletcher G, Gee I, et al. IPEADAM study: indoor endotoxin exposure, family status, and some housing characteristics in English children. J Allergy Clin Immunol 2006; 117: 656-662.

18 Haverinen-Shaughnessy U, Borras-Santos A, Turunen M, et al. Occurrence of moisture problems in schools in three countries from different climatic regions of Europe based on questionnaires and building inspections - the HITEA study. Indoor Air 2012 2012; 22: 457-466.

19 Haverinen-Shaughnessy U, Hyvarinen A, Pekkanen J, et al. Occurrence and characteristics of moisture damage in residential buildings as a function of occupant and engineer observations. Indoor Built Environ 2005; 14: 133-140.

20 Asher MI, Keil U, Anderson HR, et al. International Study of Asthma and Allergies in Childhood (ISAAC): rationale and methods. Eur Respir J 1995; 8: 483-491.

21 Miller MR, Hankinson J, Brusasco V, et al. Standardisation of spirometry. Eur Respir J 2005; 26: 319-338.

22 Doekes G, Douwes J, Wouters I, et al. Enzyme immunoassays for total and allergen specific IgE in population studies. Occup Environ Med 1996; 53: 63-70.

23 Noss I, Wouters IM, Visser M, et al. Evaluation of a low-cost electrostatic dust fall collector for indoor air endotoxin exposure assessment. Appl Environ Microbiol 2008; 74: 5621-5627.

24 Noss I, Doekes G, Sander I, et al. Passive airborne dust sampling with the electrostatic dustfall collector: optimization of storage and extraction procedures for endotoxin and glucan measurement. Ann Occup Hyg 2010; 54: 651-658.

25 Almqvist C, Larsson PH, Egmar AC, et al. School as a risk environment for children allergic to cats and a site for transfer of cat allergen to homes. J Allergy Clin Immunol 1999; 103: 1012-1017.

26 Janssen NA, Hoek G, Harssema H, et al. Childhood exposure to PM10: relation between personal, classroom, and outdoor concentrations. Occup Environ Med 1997; 54: 888-894.

27 Simoni M, Annesi-Maesano I, Sigsgaard T, et al. School air quality related to dry cough, rhinitis and nasal patency in children. Eur Respir J 2010; 35: 742-749.

28 Oeder S, Dietrich S, Weichenmeier I, et al. Toxicity and elemental composition of particulate matter from outdoor and indoor air of elementary schools in Munich, Germany. Indoor Air 2012; 22: 148-158.

29 Andersson AM, Weiss N, Rainey F, et al. Dust-borne bacteria in animal sheds, schools and children's day care centres. J Appl Microbiol 1999; 86: 622-634.

30 Park JH, Cox-Ganser J, Rao C, et al. Fungal and endotoxin measurements in dust associated with respiratory symptoms in a water-damaged office building. Indoor Air 2006; 16: 192-203. 